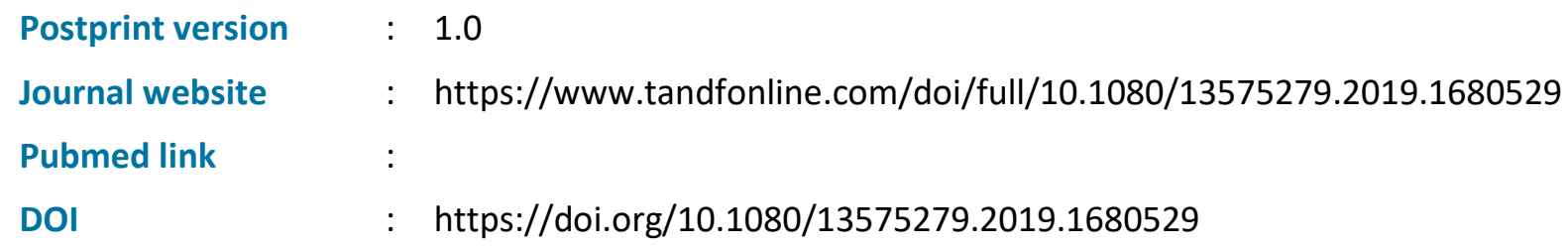

This is a Nivel certified Post Print, more info at nivel.nl

\title{
"We Know What We Are Talking about": Experiences of Young People with a Chronic Condition Involved in a Participatory Youth Panel and Their Perceived Impact
}

\section{Femke van Schelven ${ }^{a}$, Hennie Boeije ${ }^{a}$, Maj-Britt Inhulsen ${ }^{a, b}$, Jane Sattoe ${ }^{a, c}$ and Jany Rademakers ${ }^{a, d}$}

a Department Perspective of Patients and Clients in Healthcare, Netherlands Institute for Health Services Research, Utrecht, The Netherlands

b Department of Health Sciences, Faculty of Science, Vrije Universiteit, Amsterdam, The Netherlands

c Research Centre Innovations in Care, Rotterdam University of Applied Sciences, Rotterdam, The Netherlands

d Department of Family Medicine, Care and Public Health Research Institute (CAPHRI), Maastricht University, Maastricht, The Netherlands

\footnotetext{
Abstract

There is a growing recognition that research and implementation projects should be carried out "with" or "by" young people with chronic conditions, instead of "about" or "for" them. The current study aimed to explore how young people with chronic conditions experience their involvement in a participatory youth panel. This panel was a structural part of a three-year program addressing the social position of young people with chronic conditions in the Netherlands. It hosted 45 research and implementation projects to improve the social position of young people with chronic conditions in five areas: care, school, work, sport, and personal strength. Output from these projects were, for example, a tool to improve self-management, an evidence-based method to facilitate the transition to adult-care, and a digital platform about performing physical activity with a disability. During the program, six focus groups consisting of four to eleven panel members were conducted. The transcripts were analysed using the principles of thematic analysis. The results show panel members took part in multiple
} 
Schelven, F. van, Boeije, H., Inhulsen, M.B., Sattoe, J., Rademakers, J. "We Know What We Are Talking about": Experiences of Young People with a Chronic Condition Involved in a Participatory Youth Panel and Their Perceived Impact. Child Care in Practice, 2019, 27(2), p. 191-207

projects and activities, such as assessing project applications, evaluating the progress of projects and organizing a political lobby. They were enthusiastic about their role in the panel. The structural nature of the panel enabledthem to achieve personal growth and professionalization of their participation. Consequently, panel members experienced an increasing impact on the program and separate projects, and on national politics. Therefore, it is suggested that a structural form of participation, such as a participatory panel, is suitable to facilitate meaningful participation of young people with chronic conditions.

\section{Introduction}

It is widely recognized that young people with chronic conditions experience social disadvantages compared to their peers. Studies have reported that having a chronic condition complicates, for example, performing at school (Lum et al., 2017), achieving developmental milestones (Stam, Hartman, Deurloo, Groothoff, \& Grootenhuis, 2006) and social participation (Sattoe, Hilberink, Van Staa, \& Bal, 2014; Taylor, Gibson, \& Franck, 2008). Therefore, considerable research has investigated ways to improve opportunities of these young people and has targeted different areas, such as health care (Sattoe et al., 2015), sport (Willis et al., 2017) and school (Canter \& Roberts, 2012).

To resolve social disadvantages, research projects (e.g. scientific projects aimed at increasing knowledge on how young people's opportunities can be improved) and implementation projects (e.g. practice-oriented projects aimed at developing, for example, tools and interventions to enhance their social position) have been developed. Traditionally, researchers and policy makers have focused on carrying out these types of projects "about" or "for" young people with chronic conditions (INVOLVE, 2013). In more recent years, there has been growing recognition that projects should be carried out "with" or even "by" them. It is emphasized that these young people have the right to participate in decision making that concerns them. Hart (Hart, 1992) defined this type of participation as "the process of sharing decisions which affect one's life and the life of the community in which one lives".

Researchers stress the importance of participation, since it benefits both young people, and research and implementation projects. Participation contributes to the personal and social development of chronically ill young people by providing them with opportunities to gain new knowledge and skills (Bailey, Boddy, Briscoe, \& Morris, 2015; Bruce \& Parker, 2012; Dedding, 2009; Lightfoot \& Sloper, 2003), to build a social network (Bailey et al., 2015; Lightfoot \& Sloper, 2003) and to increase their independence, confidence and self-esteem (Bailey et al., 2015; Bruce \& Parker, 2012; Canter \& Roberts, 2012). Furthermore, several studies have pointed out that youth participation increases the relevance and quality of research (Bailey et al., 2015; Rosen-Reynoso et al., 2010).

There are, however, some practical limitations to involving young people with chronic conditions in projects. For example, projects in which their participation is part of the design are usually less efficient, and demand more time and resources than non-participatory projects (Bailey et al., 2015; Rosen-Reynoso et al., 2010; Van Staa, Jedeloo, Latour, \& Trappenburg, 2010). Moreover, the contribution of young people is not always of good quality due to limited skills necessary to be a suitable partner in projects (Dedding, 2009; Van Staa et al., 2010). Another challenge is maintaining their enthusiasm through all phases of a project (Bailey et al., 2015; Van Staa et al., 2010). The levels of participation can decrease during projects primarily due to disappointment about the meaningfulness of their participation. To address these challenges, it is argued that we should search for more effective and efficient forms of participation (Bailey et al., 2015; Van Staa et al., 2010).

According to Sinclair (2004), the practical limitations of participation can be overcome by introducing forms of participation that are "embedded within organisations, part of the mainstream, rather than an isolated or marginalised activity". Virtually all current studies describe participation 
Schelven, F. van, Boeije, H., Inhulsen, M.B., Sattoe, J., Rademakers, J. "We Know What We Are Talking about": Experiences of Young People with a Chronic Condition Involved in a Participatory Youth Panel and Their Perceived Impact. Child Care in Practice, 2019, 27(2), p. 191-207

forms that involve young people with chronic conditions during one project (Bruce \& Parker, 2012; Dedding, 2009; Rosen-Reynoso et al., 2010; Van Staa et al., 2010). However, following Sinclair's line of reasoning, it is necessary to move beyond these isolated forms of participation towards structural and embedded forms of participation, that provide young people with a meaningful position within an organization, allowing them to participate in multiple projects and activities over a longer period. This may increase the effectiveness of participation, since it facilitates an ongoing dialogue between young people and professionals and prevents "consultation fatigue" as a result of separate and unconnected participation activities (Sinclair, 2004). However, thus far no studies have investigated whether structural and embedded participation is suitable for young people with chronic conditions.

A possible arrangement of this type of participation is in the form of a panel of young people with chronic conditions. A participatory panel is a group of people that advise, both solicited and unsolicited, on matters that affect them with the aim to improve the relevance and quality of decisions within an organization. A panel is an integral part of the organization, and facilitates participation in multiple activities over a longer period. As it resembles existing "adult-oriented" political models, it is familiar to professionals and relatively easy to implement (Hill, Davis, Prout, \& Tisdall, 2004; Matthews, 2001).

The current study aims to explore how young people with chronic conditions experience their involvement in a participatory youth panel. Chronic conditions are defined as conditions "that lasted or are expected to last twelve or more months and resulted in functional limitations and/or the need for ongoing medical care" (Hwang, Weller, Ireys, \& Anderson, 2001). The study was conducted among the youth panel within the Dutch program Care and Future Prospects [in Dutch: Zorg én Perspectief] (CFP). A description of the program and the youth panel is presented in Box 1 . The following research questions were examined:

- How do young people with chronic conditions experience their participation in a youth panel, and how does this affect them?

- What impact do young people with chronic conditions participating in a youth panel experience on research and implementation projects that aim to foster the social position of this group?

- What factors facilitate or impede the impact of a panel of young people with chronic conditions?

\section{[Box 1]}

\section{[Table 1]}

The findings contribute to a growing body of knowledge about how young people with chronic conditions can play an active role in research and implementation projects that affect them.

\section{Materials and methods}

\section{Study design}

Six focus groups were conducted to explore experiences and opinions with regard to participation in the youth panel of CFP. Initially, online focus groups (OFGs) were chosen, since they provide participants with the possibility to participate a-synchronously at a time and place convenient to them (Zwaanswijk \& Van Dulmen, 2014). However, during the study, it became clear that most participants found the OFGs an inconvenient way of sharing their experiences. Moreover, the chairman of the youth panel noted that some relevant topics were not discussed during the OFGs. Therefore, the last four focus groups were conducted face-to-face (FFGs). Participants preferred this way of data collection, since it improved interaction and facilitated in-depth discussions. This, in turn, led to richer data, since they were more willing to share their experiences. 
Schelven, F. van, Boeije, H., Inhulsen, M.B., Sattoe, J., Rademakers, J. "We Know What We Are Talking about": Experiences of Young People with a Chronic Condition Involved in a Participatory Youth Panel and Their Perceived Impact. Child Care in Practice, 2019, 27(2), p. 191-207

During the OFGs and FFGs, a topic list was used to structure the focus groups (Appendix A). As new questions arose during data collection, the topic list was adapted during the course of the study. Themes on the different versions of the topic lists were, for example, the overall functioning of the youth panel, development of the youth panel and its activities and impact. All versions were reviewed and approved by the previous and current chairman of the youth panel. During all focus groups, participants were also free to suggest their own themes.

\section{Participants}

All members of the youth panel received an email inviting them to participate in the focus groups. Overall, 24 panel members participated in one or multiple focus groups in the period from July 2016 to October 2018.

\section{[Table 2]}

The OFGs took place in July 2016 and January 2017. Each OFG consisted of six to eleven participants (Table 2). The FFGs were held in September 2017 and October 2018. Due to the large number of participants, the participants of the FFGs were split into two smaller groups. This resulted in FFGs with four to eight participants.

In all focus groups, the majority of the panel members at that time participated. Reasons for nonresponse were conflicts of interest due to prior obligations, lack of time, temporarily living abroad, or illness.

\section{Data collection}

During OFG 2 and FFG 3, two young people with a chronic condition (not otherwise part of the program or the panel) were involved in data collection as co-researchers. They assisted the researchers in moderating the focus groups, for example, by asking followup questions. Based on the results of earlier studies (Dedding, 2009; Lightfoot \& Sloper, 2003; Schalkers, Parsons, Bunders, \& Dedding, 2016), it was believed that this would increase the quality of the data collection, since the co-researchers could help focussing on relevant topics. However, due to illness and other obligations, the co-researchers were not able to assist during all focus groups. The focus groups without the coresearchers were performed by a team of researchers, of which at least one was a young researcher of the same age as the participants.

The OFGs were organized using a closed web-based discussion site. Participants received an email with the starting date of the OFG, the website link and their personal login names and passwords. Within a set period of three weeks participants could log in, read each other's anonymous comments and give their online responses at any time. One question or statement was posted every 2-3 days. The remaining days were used to give participants the opportunity to respond to questions of previous days and to the reactions of other participants. Two researchers (H.B. and M.I.) (OFG 1), or two researchers (H.B. and M.I.) and two co-researchers (OFG 2) moderated and monitored the discussion and asked more in-depth questions when necessary. All topics remained open for response throughout the whole study period. At the end of the OFGs the discussion site provided a complete and literal transcript of all reactions.

The FFGs were moderated by a team of one researcher (H.B.) and a co-researcher (FFG 3), or two researchers (F.S., H.B., M.I. and/or J.S.) (FFG 4-6). The FFGs lasted approximately $45-90$ min, were audio-recorded and transcribed verbatim.

\section{Data analysis}

For both the OFGs and the FFGs, a qualitative analysis method inspired by thematic analysis (Braun \& Clarke, 2006) was used. All transcripts were analysed by the principal researcher (F.S.), and the first 
Schelven, F. van, Boeije, H., Inhulsen, M.B., Sattoe, J., Rademakers, J. "We Know What We Are Talking about": Experiences of Young People with a Chronic Condition Involved in a Participatory Youth Panel and Their Perceived Impact. Child Care in Practice, 2019, 27(2), p. 191-207

four transcripts were also independently analysed by another researcher (H.B. or M.I.). Relevant excerpts were marked and coded. Initially, codes were chosen that were close to participants' wording, such as "receiving opportunities" and "contributing to a better world". Related codes were then grouped to identify subthemes and themes related to the research questions. For example, "receiving opportunities" became a subtheme of the overall theme "personal development", and "contributing to a better world" was added to the overall theme "motivation". Two researchers (F.S. and H.B.) discussed the codes and themes of the first four transcripts. Following the discussions, some themes were adapted, merged or renamed. After identifying the codes and the themes, the relationships between themes were analysed. These were also discussed, until consensus was reached (F.S., H.B. and J.S.). The MAXQDA-11 software package was used as an aid in the coding process.

\section{Results}

In the analysis of the experiences of the youth panel of the Dutch program CFP, six themes were identified: (i) motivation, (ii) participation, (iii) impact, (iv) facilitating factors, (v) impeding factors, and (vi) the future. All findings were derived from the reports of participants.

\section{Motivation}

The participating panel members reported different reasons for participating in the CFP youth panel. An important reason was that participation allowed them to do something for others, despite their chronic condition. Their chronic condition became a strength, rather than a weakness, and they could use it to improve the social position of other young people with chronic conditions.

What I really like about the panel is that my experiences, my daily barriers, are useful. I can use them and help others. I can finally turn my shit [into something positive]. - FFG 3, female, 24

Furthermore, panel members stipulated it is important to incorporate their perspective in decisions related to the CFP program and the projects it hosts, as they are familiar with the problems young people with chronic conditions experience and are therefore able to provide new insights.

It [the youth panel] is most valuable, when we can provide insights other people did not think about. Or when we have a different opinion about a project than the program committee, or something. Then, I think, the participation and the youth panel are most valuable, because it really adds something. Yes, we know what we are talking about. We have experienced it. - FFG 4, male, 24

Panel members also reported they participated in the youth panel to raise awareness about having a chronic condition and to contribute to a better world. Furthermore, some of them participated, since they were enthusiastic about the program or since they enjoyed being a member of the youth panel.

\section{Participation of the youth panel}

Initially, panel members predominantly participated in the CFP program and the projectswithin the program. During the program, the activities of the youth panel shifted towards national politics. Simultaneously, panel members experienced a professionalization and an increasingly structured organization of the youth panel. At the start of the panel, they were collectively responsible for all tasks within the youth panel, but, over the course of the program, tasks were divided over the five themes of the CFP program: care, school, work, sports, and personal strength. 
Schelven, F. van, Boeije, H., Inhulsen, M.B., Sattoe, J., Rademakers, J. "We Know What We Are Talking about": Experiences of Young People with a Chronic Condition Involved in a Participatory Youth Panel and Their Perceived Impact. Child Care in Practice, 2019, 27(2), p. 191-207

Over time and through experience and training in, for example, promoting their interests, panel members improved their skills in conveying an overall message, instead of each panel member telling their individual story.

At first, there was nothing. Now there is structure, since a year. The first half a year was less clear: where are we going? Now we are a structured panel. - FFG 3, female, 24

\section{Participation in the program and the projects}

Panel members were predominantly positive about their involvement in the CFP program. The program provided them with opportunities to share their opinions. However, the roles they took on within the youth panel varied. For example, some panel members were provided with additional tasks, such as writing blogs, speaking on conferences, or making movies. These differences increased during the program, because of changes within the program: the proportion of project-related activities decreased, as more projects were finished. Subsequently, panel members were more often provided with the choice to engage in alternative activities.

Yes, we want to give panel members space to choose. We don't want to oblige them to do A or B. However, that does imply more diverse roles in the panel. - FFG 5, female, 20

There was considerably more debate among panel members about the involvement within the projects the program hosts. Although their involvement in the hosted projects increased as the youth panel grew and developed, there was a great variation in the extent to which project leaders informed and consulted the youth panel. Some panel members were a partner in the data collection of a research project or advised on the implementation of a tool, whilst other panel members were solely informed about the progress of the project or not informed at all. Panel members suggested that their involvement depended on the type of project and on the value project leaders placed on their perspective.

Some projects avoid contact, some want you to participate in every meeting and others have no idea what to do with us, I believe. - OFG 2, female, 22

\section{Participation in the national politics}

According to the panel members, their participation in the CFP program and the projects was not sufficient to improve the social position of young people with chronic conditions. Therefore, they increasingly engaged in political activities such as organizing conversations with members of the Dutch parliament and Ministers, and sending position papers to the spokesmen of political parties. At first, these activities were primarily the initiative of the youth panel. However, over time, the demand for consultations outside of the program by, for example, politicians grew.

I have the feeling that we are increasingly invited to participate. Initially, we usually sent the letters. That was about politics, that we wanted to meet. Now, we are increasingly invited to join in conversations or meetings. That is really cool. - FFG 6, male, 25

\section{Impact of the youth panel}

Panel members were enthusiastic about the impact of the youth panel. They felt listened to and taken seriously. According to them, their influence increased during the program, since the youth panel developed and panel members knew better how to influence decision making. However, they recognized, and found it logical and desirable, that final decisions were always made by the projects and the program themselves. Overall, the panel members reported impact of the youth panel on three levels: themselves, the program and the projects, and the national politics. 
Schelven, F. van, Boeije, H., Inhulsen, M.B., Sattoe, J., Rademakers, J. "We Know What We Are Talking about": Experiences of Young People with a Chronic Condition Involved in a Participatory Youth Panel and Their Perceived Impact. Child Care in Practice, 2019, 27(2), p. 191-207

I don't feel like a showpiece [of CFP and FNO]. I most certainly feel like FNO does something with our opinions and input and they did not only add us to the program as decoration. - OFG 2 , female, 25

\section{Impact on the panel members themselves}

An important personal benefit of participating in the youth panel was that it offered panel members opportunities for personal development. Panel members explained that establishing changes in the program or projects increased their confidence, which provided them with the courage to take on a greater role within the youth panel. By accomplishing their tasks in the panel they were able to improve their skills, such as public speaking and conveying their message. Besides, being a panel member offered them new opportunities, such as speaking in front of an audience, getting in contact with politicians and going to conferences. Panel members also reported that they learned from each other; experienced panel members shared their knowledge and experiences with new, inexperienced panel members.

Another valuable outcome of participation in the youth panel was network building, both private and business-related. Panel members emphasized that involvement in the youth panel increased social contacts with peers who also deal with a chronic illness or disability. This resulted in close friendships. Furthermore, some of them mentioned that the youth panel facilitated building a business-related network by making it easier to get in contact with professional parties.

We get to think about things I didn't even know existed, we get to open doors that otherwise would remain closed, we get to look behind the scenes and we can think, contribute and read along with the program. - OFG 1, female, 18

\section{Impact on the program and the projects}

The youth panel had an increasing impact on the assessment of project applications in CFP. During the first call of the program, only the chairman was involved in the assessment of project applications. The other panel members were asked for feedback, after a decision was made. However, since the youth panel provided valuable feedback, it was decided to involve all panel members in the assessment of project applications in the subsequent calls. In the fourth and last call, the suggestions of the panel members were considered decisive in the assessment of project applications.

Furthermore, panel members agreed that involving the youth panel contributed to an improvement of the projects. According to them, project leaders frequently made false assumptions about, or were unfamiliar with the experiences of young people with chronic conditions. The involvement of the youth panel contributed to a better alignment of the projects with the perceptions of young people with chronic conditions.

You can't work for a group, without involving them. That is the biggest mistake that is always made, that young people are talked about and not with. So without the youth panel projects [will miss their goal]. - FFG 5, female, 25

\section{Impact on the national politics}

The panel members experienced impact of their political activities. This impact primarily consisted of creating awareness about the problems experienced by young people with chronic conditions. For example, some panel members had a meeting with the Dutch Minister of Education about the barriers of studying with a chronic condition. The reaction of the Minister proved that a lot of their problems were unknown to her. 
Schelven, F. van, Boeije, H., Inhulsen, M.B., Sattoe, J., Rademakers, J. "We Know What We Are Talking about": Experiences of Young People with a Chronic Condition Involved in a Participatory Youth Panel and Their Perceived Impact. Child Care in Practice, 2019, 27(2), p. 191-207

Panel members experienced that their political activities contributed more directly to the social position of young people with chronic conditions than their activities in CFP. According to them, in projects, their contribution depended on the project leaders, but the political activities were their own initiative and responsibility. Moreover, they expected that their impact on politics had a greater reach than their impact on the projects.

I was present at a meeting with a politician. That was the first time. And we sat there together, with all those young people, and we wrote down all kinds of things. And the man with the suit told us: yes, I'm really going to use this. [...]. Then I really thought: someone's listening! [...] He was there, and he heard us. - FFG 5, female, 25

\section{Facilitating factors for participation}

Participants reported some factors that could enhance their participation. For instance, an important facilitating factor was providing panel members with feedback on their work. This would improve their learning process and thereby their future advice. Although the program has formulated guidelines for providing feedback, it was not always clear to panel members whether and how project leaders included their advice in projects.

Some feedback would be nice. Sometimes it is hard to advise on the program or a project and you wonder whether you are looking at it the right way. - OFG 2, female, 23

Another facilitating factor was transparency about decisions related to the program and the youth panel. During the first focus groups, some participants experienced receiving fewer opportunities for participation compared to other panel members. Moreover, CHILD CARE IN PRACTICE 9 panel members were not always informed in a timely manner about program-related decisions. This caused incomprehension and feelings of disappointment and discomfort. Therefore, they suggested that transparency would create more understanding and support for decisions in programs and projects. Consequently, the transparency of program-related decisions was increased during the program. Yet, some panel members still felt they received less opportunities than others to participate.

I have asked several times for additional tasks. They [the CFP program] answer that they will come back to it, but they never do. - FFG 6, female, 18

A facilitating factor already present in the youth panel, included, for example, the participation policy of the program. All projects in the CFP program were obliged to involve the youth panel. This increased the influence of the youth panel. However, sometimes it also contributed to tokenism: panel members experienced that some project leaders solely involved them to comply with the rules, but did not include their contribution in projectrelated decisions.

It depends on whether they see the added value of it or just want the funds. That makes a difference. [...] They contact us, because it is in the terms and conditions, but if they don't see the added value, they won't do anything with the information. - FFG 3, female, 17

Another facilitating factor already present in the youth panel was the collective voice and the stage it provided to present ideas and opinions. Panel members believed this also aided them in influencing the program and projects.

You are provided with a stage. Since we are a part of FNO, our reach is wider and we are given a voice. It is already in us, and here we are provided with the chance to put it into practice, 
Schelven, F. van, Boeije, H., Inhulsen, M.B., Sattoe, J., Rademakers, J. "We Know What We Are Talking about": Experiences of Young People with a Chronic Condition Involved in a Participatory Youth Panel and Their Perceived Impact. Child Care in Practice, 2019, 27(2), p. 191-207

and that is really nice. - FFG 3, female, 25

\section{Factors impeding participation}

Panel members reported three factors impeding the participation of the youth panel. Firstly, they stressed that attention should be paid to the capacities of the youth panel. Being a member of the panel increasingly demanded time and effort, due to the success of the panel and the subsequent growth in requests from the program and its projects. Panel members found this difficult, since most of them combined their activities in the youth panel with studying or a job. Their chronic condition could also hinder them in responding to these requests, for example, when they had to be hospitalized or when they felt ill or tired.

The second challenge concerned the recruitment of new panel members. Panel members experienced that it is hard to find young people with chronic conditions, since they are mostly anonymous. Moreover, they suggested that some young people with chronic conditions are not willing to be a panel member, since it focuses too much on them having a chronic condition.

Yes, also because, when you have found the young people, not everyone wants to participate.

Look, we are all very enthusiastic and want to share our experiences. However, I can also imagine, and I also know young people that think: oh, please, leave me alone. Let me figure out my own life. - FFG 4, female, 26

Finally, panel members recognized that the continuation of the youth panel strongly depends on the program and the organization responsible for the program. The program and the organization offered the means to organize activities, and to financially reward panel members for their efforts. Moreover, they thought the youth panel needed the support of the program to be taken seriously by external partners.

We can't do it without [the organisation]. They won't listen, not much anyway. That there is an organisation supporting us, gives us more power. - FFG 5, female, 25

\section{The future}

Panel members agreed that the youth panel should continue in the future. In the past three years, the panel developed a clear structure and a solid base of knowledge. Moreover, they argued that the projects should always - also in the future-include young people with chronic conditions in their decision making, and that a youth panel is a good way to facilitate this.

The projects will continue. And they always have to, should have to, keep looking for young people. And I think the youth panel is a very good organization to facilitate this. - FFG 4, male, 21

Furthermore, several panel members expressed a wish to increase the political engagement of the youth panel. They would like to not only influence the program and its projects, but also the national political agenda. They wished to contribute to the improvement of the social conditions of young people with chronic conditions in a broader setting than solely within the CFP program. A dream for most panel members is for the youth panel to become a recognized advisory partner in national policy issues regarding young people with chronic conditions.

For me, the ultimate dream is to become some kind of platform for young people with chronic conditions. Not just for the young people themselves, but also as a recognized partner of organisations and Ministries. That they will think: if we have to make decisions about this subject, we have to consult the youth panel. - FFG 5, female, 25 
Schelven, F. van, Boeije, H., Inhulsen, M.B., Sattoe, J., Rademakers, J. "We Know What We Are Talking about": Experiences of Young People with a Chronic Condition Involved in a Participatory Youth Panel and Their Perceived Impact. Child Care in Practice, 2019, 27(2), p. 191-207

\section{Discussion}

The current study has investigated the experiences of young people with chronic conditions participating in a youth panel, the perceived impact of their participation, and factors that can facilitate or impede the impact of their participation.

The results imply a youth panel is a suitable way to facilitate participation of young people with chronic conditions in multiple research and implementation projects and activities over a longer period of time. The finding that panel members were enthusiastic about their role in the youth panel supports previous work reporting that young people with chronic conditions are generally able and willing to participate (Cherrill et al., 2010; Lightfoot \& Sloper, 2003). However, panel members in this study were also ambitious to continue and expand their influence, suggesting that they value the structural participation in a youth panel.

The benefits of participation for panel members are similar to benefits reported in previous studies. Participation contributes to personal development (Bailey et al., 2015; Dedding, 2009; Murray, 2015; Turtle, McElearney, \& Scott, 2010; Van Staa et al., 2010) and network building (Bailey et al., 2015; Lightfoot \& Sloper, 2003; Murray, 2015) of participants. The current study adds that the structural nature of a youth panel contributes to a continuing development of panel members, since it allows panel members to apply learning experiences from one project to subsequent projects. Through this, panel members undergo some degree of "professional socialisation" (Ives, Damery, \& Redwod, 2013). As the panel developed, this process of professional socialization accelerated, since experienced panel members could "teach" newer panel members, based on their experiences.

According to Ives et al. (2013), professional socialization is needed for participants to make a substantial contribution to projects. Therefore, the finding that the youth panel reported a positive impact of their participation on projects is not surprising. Although previous work has also found that participation can improve the relevance and quality of projects (Bailey et al., 2015; Rosen-Reynoso et al., 2010; Turtle et al., 2010), this study adds that panel members experienced that their impact increased over time. As a result of their personal development and the development of the panel as a whole, their perceived influence increased both within and outside of the CFP program.

Although the professional socialization contributed to an increased impact of the youth panel, some researchers have warned that it may compromise the ability of participants to authentically reflect the lay perspective (Ives et al., 2013; Martin \& Finn, 2011). In the process of professional socialization participants learn to adopt explanations and interpretations of the professionals with whom they collaborate (Thompson, Bissell, Cooper, Armitage, \& Barber, 2012). However, this theory has been disputed and it is argued that participants can combine experiential and professional knowledge (Staley, 2013). Moreover, the opinions of the panel members in the current study frequently differed from those of the program committee of CFP, suggesting they were able to combine their increasing professionalism with their experiential "lay" knowledge.

In addition to the professionalization of the panel, several other factors were uncovered that facilitate the impact of a youth panel. These factors share similarities with factors found in previous studies. Facilitating factors are, for example, providing panel members with feedback on their work (Lightfoot \& Sloper, 2003), and equipping them with a collective voice and a stage to present their ideas and opinions (Dedding, 2009).

In the current study, transparency about program-related decisions, and establishing a formal participation policy within the program that obliged projects to involve panel members emerged as additional facilitating factors for the impact of a youth panel.

As opposed to the facilitating factors, some factors can impede the impact of a youth panel. An example of an impeding factor is the dependency on others. Panel members suggested the continuation of the youth panel depended on the program, and their involvement in projects depended on the value project leaders placed on their perspective. Similar findings were reported in previous studies (Dedding, 2009; Matthews, 2001). In the current study, the formal policy of the 
Schelven, F. van, Boeije, H., Inhulsen, M.B., Sattoe, J., Rademakers, J. "We Know What We Are Talking about": Experiences of Young People with a Chronic Condition Involved in a Participatory Youth Panel and Their Perceived Impact. Child Care in Practice, 2019, 27(2), p. 191-207

program that obliged projects to involve the youth panel offered a partial solution to the dependency on project leaders. However, it must also be noted that these rules led to forms of tokenism, when project leaders did not value the input of panel members.

Another impeding factor for the impact of a youth panel is its limited capacity, and the difficulty in recruiting new panel members. In the current study, being a panel member increasingly demanded time, due to the success of the panel. Moreover, recruiting new panel members was difficult, since not all young people with chronic conditions are willing or able to participate. These findings are in line with those of other studies (Dixon, Ward, \& Blower, 2019; Sinclair, 2004; Van de Bovenkamp, 2010; Van Staa et al., 2010). The authors of these studies have warned of creating a so-called participation elite. Involvement in formal decision making is a difficult task that requires a substantial amount of time and effort (Van de Bovenkamp, 2010). As a result, participation roles are predominantly performed by the relatively well-off. In the current study, this participation elite was also present: the youth panel consisted solely of young people that either followed or completed secondary education. None of the panel members solely followed or completed lower education. Indeed, it is likely, as was also noted by Van Staa et al. (2010), that the risk of creating a participation elite is especially present in forms of structural participation, such as the youth panel, since these require an ongoing effort instead of a onetime isolated consultation.

The purpose of the youth panel is to broaden the range of perspectives that inform decision making. Although this appears to be achieved to a considerable extent, the perspectives of the lower educated are not represented in the youth panel. As a result, the involvement of the youth panel may have predominantly contributed to a better alignment of projects and other activities with the perceptions of young people with chronic conditions, who are medium or highly educated. Therefore, future research should address the issue of equal opportunities, and investigate ways to include more lower educated young people, to ensure a diverse youth panel that represents all young people with chronic conditions

\section{Strengths, limitations and future research}

The current study was conducted among a relatively large youth panel. Due to the size and the structural nature of the CFP youth panel, it was possible to investigate the utilization of a youth panel among a substantial study sample over a longer period. However, the study also had some limitations.

During the study, it became clear that online focus groups were not appreciated by the panel members. In order to match the method of data collection to the preferences of the panel members, the initial methodology of the study was adapted and subsequent focus groups were conducted faceto-face. This improved data collection, since there was more willingness to share and more interaction, which facilitated in-depth discussions between panel members.

The findings are based on one panel of young people with chronic conditions within a Dutch program and the results may thus not apply to other settings and other countries. However, as mentioned earlier, the findings are derived from a panel participating in a program that hosted a diversity of projects in various settings (e.g. school, work, sports and care) over a period of three years, which improves generalizability. Next to this, the findings share many similarities with previous studies. However, in order to provide a more complete picture of the suitability of a youth panel to facilitate participation among young people with chronic conditions more research is needed. This research should address the utilization of a panel of young people with chronic conditions in other settings than CFP. Such a study could extend the findings of the current study by including, for example, the perspective of researchers and policy makers (Schalkers et al., 2016) and objective measurements of impact, such as project-related improvements (Bailey et al., 2015). 
Schelven, F. van, Boeije, H., Inhulsen, M.B., Sattoe, J., Rademakers, J. "We Know What We Are Talking about": Experiences of Young People with a Chronic Condition Involved in a Participatory Youth Panel and Their Perceived Impact. Child Care in Practice, 2019, 27(2), p. 191-207

\section{Conclusions and practical implications}

The current study showed that a structural and embedded participatory youth panel is a suitable way to facilitate the participation of young people with chronic conditions in multiple research and implementation projects and activities. Panel members were enthusiastic about their participation, and ambitious to expand their influence. They reported impact of their participation on themselves, on the program and projects, and on national politics. According to panel members, the structural nature of the youth panel allowed them to increase their impact over time, since it enabled professionalization of the panel and its members. Therefore, policy makers and researchers should consider structural participation forms, such as a participatory youth panel, when involving young people with chronic conditions in their projects. However, to enable the participation of all young people with chronic conditions, they should also facilitate and closely monitor the capacities of the young people involved, since structural participation requires an ongoing effort and investment.

\section{Disclosure statement}

No potential conflict of interest was reported by the authors.

\section{Funding}

The project is funded by Fonds NutsOhra, Amsterdam.

\section{Notes on contributors}

Femke van Schelven holds a Bachelor's degree in Health \& Society from Wageningen University, and a Master's degree in Youth Studies from the Utrecht University. Currently, she is a researcher and Ph.D. student at Nivel, the Netherlands institute for Health Services Research. Her research focuses on the inclusion and participation of young people with a chronic condition.

Hennie Boeije (Ph.D., sociologist) is coordinator at Nivel of the research programme into people with chronic illness and disability. Within this programme, studies are being done into quality of life, selfmanagement and integrated care, societal participation including employment and care for the elderly. For 15 years, she was an associate professor in qualitative research methods in the social sciences at Utrecht University. Hennie published academic books and numerous papers in the field of qualitative research methodology and health care and related issues.

Maj-Britt Inhulsen holds a master's degree in Health Sciences and is specialized in the topic of prevention and public health. She works as a Ph.D. student at the department of Health Sciences at the Vrije Universiteit Amsterdam. Her previous work focused on living and participating with a chronic condition, with a particular focus on youth. Currently, her research focuses on the promotion of sleep behavior in youth.

Jane Sattoe, Ph.D., is a Senior Researcher and Senior Lecturer at Rotterdam University of Applied Sciences in Rotterdam, The Netherlands. Her research is primarily focused on self-management of young people growing up with chronic conditions.

Prof. Jany Rademakers is research department head and member of the management team of NIVEL, the Netherlands institute for Health Services Research. She is also professor Health literacy and patient participation at Maastricht University (CAPHRI). Her research focuses on diversity in health care, more specific on health literacy and patient activation, and in general on patient involvement and empowerment in health care. She is a member of the steering committee and chair of the working group on patient experiences of the Dutch Alliance for Health literacy. 
Schelven, F. van, Boeije, H., Inhulsen, M.B., Sattoe, J., Rademakers, J. "We Know What We Are Talking about": Experiences of Young People with a Chronic Condition Involved in a Participatory Youth Panel and Their Perceived Impact. Child Care in Practice, 2019, 27(2), p. 191-207

\section{References}

Bailey, S., Boddy, K., Briscoe, S., \& Morris, C. (2015). Involving disabled children and young people as partners in research: A systematic review. Child: Care, Health and Development, 41(4), 505-514. doi:10.1111/cch.12197

Braun, V., \& Clarke, V. (2006). Using thematic analysis in psychology. Qualitative Research in Psychology, 3(2), 77-101. doi:10.1191/1478088706qp063oa Bruce, S. M., \& Parker, A. T. (2012). Young deafblind adults in action: Becoming self-determined change agents through advocacy. American Annals of the Deaf, 157(1), 16-26. doi:10.1353/aad. 2012.1607

Canter, K. S., \& Roberts, M. C. (2012). A systematic and quantitative review of interventions to facilitate school reentry for children with chronic health conditions. Journal of Pediatric Psychology, 37(10), 1065-1075. doi:10.1093/jpepsy/jss071

Cherrill, J., Hudson, H., Cocking, C., Unsworth, V., Franck, L., Fakis, A.,...Choonara, I. (2010). Clinical trials: The viewpoint of children with a chronic illness compared with healthy children. Archives of Disease in Childhood, 95(3), 229-232. doi:10.1136/adc.2009.159145

Dedding, C. (2009). Delen in macht en onmacht (PhD diss.). Faculteit der Maatschappij- en Gedragswetenschappen. Universiteit van Amsterdam.

Dixon, J., Ward, J., \& Blower, S. (2019). "They sat and actually listened to what we think about the care system": The use of participation, consultation, peer research and co-production to raise the voices of young people in and leaving care in England. Child Care in Practice, 25(1), 6-21. doi:10. 1080/13575279.2018.1521380

Hart, R. A. (1992). Childrens participation: From tokenism to citizenship. Florence: UNICEF International Child Development Centre.

Hill, M., Davis, J., Prout, A., \& Tisdall, K. (2004). Moving the participation agenda forward. Children \& Society, 18(2), 77-96. doi:10.1002/chi.819

Hwang, W., Weller, W., Ireys, H., \& Anderson, G. (2001). Out-of-pocket medical spending for care of chronic conditions. Health Affairs, 20(6), 267-278. doi:10.1377/hltaff.20.6.267

INVOLVE. (2013). Approaches to public involvement in research. Retrieved from https://www.invo. org.uk/posttyperesource/approaches-to-public-involvement/

Ives, J., Damery, S., \& Redwod, S. (2013). PPI, paradoxes and plato: Who's sailing the ship? British Medical Journal, 39, 181-185. doi:10.1136/medethics-2011-100150

Lightfoot, J., \& Sloper, P. (2003). Having a say in health: Involving young people with a chronic illness or physical disability in local health services development. Children \& Society, 17(4), 277-290.

doi:10.1002/chi.748

Lum, A., Wakefield, C. E., Donnan, B., Burns, M. A., Fardell, J. E., \& Marshall, G. M. (2017). Understanding the school experiences of children and adolescents with serious chronic illness: $A$ systematic meta-review. Child: Care, Health and Development, 43(5), 645-662. doi:10.1111/ cch. 12475

Martin, G. P., \& Finn, R. (2011). Patients as team members: Opportunities. Challenges and paradoxes of including patients in multi-professional healthcare teams. Sociology of Health and IIIness, 33(7), 1050-1065. doi:10.1111/j.1467-9566.2011.01356.x

Matthews, H. (2001). Citizenship, youth councils and young people's participation. Journal of Youth Studies, 4(3), 299-318. doi:10.1080/13676260120075464

Murray, R. (2015). Yes they are listening but do they hear us? Reflections on the Journey of the Barnardo's Participation Project. Child Care in Practice, 21(1), 78-90. doi:10.1080/13575279. 2014.973370

Rosen-Reynoso, M., Kusminsky, M., Gragoudas, S., Putney, H., Crossman, M. K., Sinclair, J., \& Yarde, J. (2010). Youth-based participatory research: Lessons learned from a transition research study. Pediatrics, 126(Suppl. 3), 177-182. doi:10.1542/peds.2010-1466N 
Schelven, F. van, Boeije, H., Inhulsen, M.B., Sattoe, J., Rademakers, J. "We Know What We Are Talking about": Experiences of Young People with a Chronic Condition Involved in a Participatory Youth Panel and Their Perceived Impact. Child Care in Practice, 2019, 27(2), p. 191-207

Sattoe, J. N. T., Bal, M. I., Roelofs, P. D. D. M., Bal, R., Miedema, H. S., \& Van Staa, A. (2015). Selfmanagement interventions for young people with chronic conditions: A systematic overview. Patient Education and Counseling, 98(6), 704-715. doi:10.1016/j.pec.2015.03.004

Sattoe, J. N. T., Hilberink, S. R., Van Staa, A., \& Bal, R. (2014). Lagging behind or not? Four distinctive social participation patterns among young adults with chronic conditions. Journal of Adolescent Health, 54(4), 397-403. doi:10.1016/j.jadohealth.2013.09.017

Schalkers, I., Parsons, C. S., Bunders, J. F., \& Dedding, C. (2016). Health professionals' perspectives on children's and young people's participation in health care: A qualitative multihospital study. Journal of Clinical Nursing, 25(7-8), 1035-1044. doi:10.1111/jocn.13152

Sinclair, R. (2004). Participation in practice: Making it meaningful, effective and sustainable. Children \& Society, 18, 106-118. doi:10.1002/CHI.817

Staley, K. (2013). There is no paradox with PPI in research. Journal of Medical Ethics, 39(3), 186187. doi:10.1136/medethics-2012-100512

Stam, H., Hartman, E. E., Deurloo, J. A., Groothoff, J., \& Grootenhuis, M. A. (2006). Young adult patients with a history of pediatric disease: Impact on course of life and transition into adulthood. Journal of Adolescent Health, 39(1), 4-13. doi:10.1016/j.jadohealth.2005.03.011

Taylor, R. M., Gibson, F., \& Franck, L. S. (2008). The experience of living with a chronic illness during adolescence: A critical review of the literature. Journal of Clinical Nursing, 17(23), 3083-3091.

doi:10.1111/j.1365-2702.2008.02629.x

Thompson, J., Bissell, P., Cooper, C., Armitage, C. J., \& Barber, R. (2012). Credibility and the 'professionalized' lay expert: Reflections on the dilemmas and opportunities of public involvement in health research. Health (London), 16(6), 602-618. doi:10.1177/1363459312441008

Turtle, K., McElearney, A., \& Scott, J. (2010). Involving children in the design and development of research instruments and data collection procedures: A case study in primary schools in Northern Ireland. Child Care in Practice, 16(1), 57-82. doi:10.1080/13575270903378443

Van de Bovenkamp, H. M. (2010). The limits of patient power: Examining active citizenship in Dutch health care (PhD diss.). Erasmus Universiteit Rotterdam.

Van Staa, A., Jedeloo, S., Latour, J. M., \& Trappenburg, M. J. (2010). Exciting but exhausting: Experiences with participatory research with chronically ill adolescents. Health Expectations,13(1), 95-107. doi:10.1111/j.1369-7625.2009.00574.x

Willis, C., Girdler, S., Thompson, M., Rosenberg, M., Reid, S., \& Elliott, C. (2017). Elements contributing to meaningful participation for children and youth with disabilities: A scoping review. Disability and Rehabilitation, 39(17), 1771-1784. doi:10.1080/09638288.2016.1207716

Zwaanswijk, M., \& Van Dulmen, S. (2014). Advantages of asynchronous online focus groups and face-to-face focus groups as perceived by child, adolescent and adult participants: A survey study. BMC Research Notes, 7(1), 756. doi:10.1186/1756-0500-7-756

\section{Appendix A: Topic list (Translated from Dutch)}

\section{Introduction (5 $\mathrm{min})$}

Theme 1: development of the youth panel (20 min)

- Current participation:

o How do you experience your roles within the program?

- How do you experience your roles within the projects?

- Discuss individual differences in experiences.

- Participation in the past:

- Have your roles changed since the start of the panel?

- What are your experiences with these developments? 
Schelven, F. van, Boeije, H., Inhulsen, M.B., Sattoe, J., Rademakers, J. "We Know What We Are Talking about": Experiences of Young People with a Chronic Condition Involved in a Participatory Youth Panel and Their Perceived Impact. Child Care in Practice, 2019, 27(2), p. 191-207

- Dreams for future participation:

- In what project phases and in what roles do you wish to participate in the future?

- Why? Can you provide some examples?

- Do you experience sufficient possibilities to accomplish these dreams?

Theme 2: current activities (10 $\mathrm{min}$ )

- What activities enabled you to make a difference?

O Why?

- What activities failed?

○ Why?

- From what activities did you learn most?

○ Why?

Theme 3: impact (10 $\mathrm{min})$

- What would the program CFP have been without the youth panel?

- Looking back, do you feel like you have been listened to sufficiently?

- What can other programs/projects learn from CFP and youth participation?

○ Is a youth panel a suitable form of youth participation compared to other forms of youth participation?

\section{Conclusion}

- Did we discuss all relevant topics? Or do you know new topics we should discuss?

\section{Tables and figures}

Box 1. The youth panel of CFP.

The Dutch organization FNO- a fund that stimulates and supports initiatives that improve the opportunities of vulnerable people - developed the program Care and Future Prospects (CFP). This program hosted 45 research and implementation projects to improve the social position of young people with chronic conditions in five areas: care, school, work, sport, and personal strength. Output from these projects were, for example, a tool to improve selfmanagement, an evidence-based method to facilitate the transition to adult-care, and a digital platform about performing physical activity with a disability.

A central element of CFP was the youth panel, that consisted of young people of 15-30 years old with chronic conditions such as rheumatism, diabetes, cerebral palsy and traumatic brain injury. Due to both new and departing members, the size of the youth panel varied from eleven to twenty-two panel members during the research period (see Table 1 for an overview of their main characteristics). Young people could apply for panel membership via the FNO website. In the selection of new panel members, attention was paid to the diversity of panel members in terms of, for example, chronic conditions, educational level and age. One of the panel members, also a young person with a chronic condition, was the chairman of the youth panel. The chairman was formally employed by FNO, and received a salary. All other panel members received a small financial reimbursement for their efforts.

Tasks of the youth panel were to inform the program CFP, the 45 projects within the program, and the national politics about the experiences of young people with chronic conditions, and to advise on possible solutions. Within the program, for example, it played a significant role in the assessment of project applications. The projects were formally obliged to involve one panel member, whom CFP assigned to them, in design, execution and implementation. Political activities included, for example, conversations with members of the Dutch parliament and Ministers, and sending position papers to the spokesmen of political parties.

The youth panel regularly organized meetings to discuss their input and activities. 
Schelven, F. van, Boeije, H., Inhulsen, M.B., Sattoe, J., Rademakers, J. "We Know What We Are Talking about": Experiences of Young People with a Chronic Condition Involved in a Participatory Youth Panel and Their Perceived Impact. Child Care in Practice, 2019, 27(2), p. 191-207

Table 1 Characteristics of panel members in the period 2016-2018

\begin{tabular}{lc}
\hline & Panel members \\
\hline$n$ & 35 \\
Gender: & $9(25.7)$ \\
Male (\%) & $26(74.3)$ \\
Female (\%) & 21.8 \\
Age at intake: & $17-27$ \\
Mean & \\
Min-max & $0(0.0)$ \\
Educational level": & $9(25.7)$ \\
Low (\%) & $24(68.6)$ \\
Medium (\%) & $2(6.7)$ \\
High (\%) & \\
Unknown (\%) & \\
\hline aEducation denotes the number of panel members that attend or completed lower, medium or higher education. "High" \\
refers to University (of Applied Sciences), "Medium" refers to secondary school and Intermediate Vocational Education, \\
and "Low" to primary school and no education.
\end{tabular}

Table 2 Participants in the focus groups.

\begin{tabular}{|c|c|c|c|c|c|c|}
\hline & \multicolumn{6}{|c|}{ Participants in focus groups } \\
\hline & OFG 1 & OFG 2 & FFG 3 & FFG 4 & FFG 5 & FFG 6 \\
\hline$n$ & 6 & 11 & 8 & 6 & 4 & 6 \\
\hline \multicolumn{7}{|l|}{ Gender } \\
\hline Male (\%) & $3(50.0)$ & $2(18.1)$ & $1(12.5)$ & $3(50.0)$ & $0(0.0)$ & $2(33.3)$ \\
\hline Female (\%) & $3(50.0)$ & $9(81.8)$ & $7(87.5)$ & $3(50.0)$ & $4(100.0)$ & $4(66.7)$ \\
\hline \multicolumn{7}{|l|}{ Age (years) } \\
\hline Mean & 22.4 & 21.7 & 22.5 & 22.8 & 22.5 & 23.4 \\
\hline Min-max & $18-27$ & $16-28$ & $17-28$ & $21-26$ & $20-25$ & $18-27$ \\
\hline \multicolumn{7}{|l|}{ Educational level ${ }^{\mathrm{a}}$ : } \\
\hline Low $(\%)$ & $0(0.0)$ & $0(0.0)$ & $0(0.0)$ & $0(0.0)$ & $0(0.0)$ & $0(0.0)$ \\
\hline Medium (\%) & $1(16.7)$ & $2(18.1)$ & $2(25.0)$ & $1(16.7)$ & $1(25.0)$ & $2(33.3)$ \\
\hline High $(\%)$ & $4(66.7)$ & $9(81.8)$ & $6(75.0)$ & $5(83.3)$ & $3(75.0)$ & $3(50.0)$ \\
\hline Unknown (\%) & $1(16.7)$ & $0(0.0)$ & $0(0.0)$ & $0(0.0)$ & $0(0.0)$ & $1(16.7)$ \\
\hline
\end{tabular}

